\title{
The Discussion on Early Education Service in Community
}

\author{
Hui Zhang \\ School of Educational Science, Mianyang Normal University, Mianyang, China
}

870814893@qq.com

\begin{abstract}
Keywords: early education; community service
Abstract. The early education of 0-3 years old infants is the beginning of lifelong education system,early education service of community for 0-3 years old infants exists some problems in China,for instance, the administrative service of community guarantees is insufficient, private early education institutions are lack of standardization, community early education is depend on kindergarten unbalanced development and the results of early education research are weak, which should take integration resources to build community education service system for 0-3 years old infants; strengthening publicity, increasing the degree of public recognition of the significance of early education for infants; establishing professional teachers,depending on community kindergartens to promote the guidance work of early childhood education.
\end{abstract}

\section{INTRODUCTION}

Early education for $0-3$ years old infants is the beginning of lifelong education system.It is the first step on human individuals from family to society. Education, from the age of zero,has become the world's action. Community, as one of the important environment of early education of infants, its particularity and richness of resources laid the foundation for early education. In 2003, the circular of 11 ministries such as the Ministry of education on education reform and development guidance notice stated that "gradually establish community-based model kindergarten Center, combining flexible and diverse forms of early childhood education early childhood education service network.And then provide early care and education services for 0-6 year-old children and their parents. "It shows that the community education services of 0-3 years old infants is not only a concern for people's livelihood public sentiment, but is a necessary requirement for education fair. It's important to carry out the work of early education for 0-3 years old infants, which is based on communities.However, due to the short time of Community construction in China, early education community service system of $0-3$ years old infants is not perfect, in terms of both theory and practice, we need more exploration and research.

\section{THE PROBLEMS OF 0-3 YEARS OLD INFANT COMMUNITY EDUCATION SERVICES IN CHINA}

Community education service of $0-3$ years old infants mainly consists of administrative services and social services . But in the current context of community, establishing communitybased early 0-3 years old education service network, is facing the early stage problems. Performance:

A. The community administrations tasks divided, service is deficient.

Community construction in China is advancing through the district management, strong community administrative and fragmentation, social services for preschool education , on their own. The health departments are responsible for child health care, nutrition and health guidance, health care management and supervision of kindergartens.Population and Family Planning Community is mainly responsible for family planning and reproductive health services, prenatal and postnatal care, improving population quality and carrying out advocacy work actively. Working committees on women and children is mainly for women and children's rights protection advocacy, as well as issues related to coordination. FMC in family education has done some advocacy work around established women's and children's activity center, organizing some cultural and artistic activities. Street is mainly responsible for day-to-day affairs, but is not involve in specific work related to 
early childhood education. Thus, a real sense of "community-based" early childhood development services has not yet been established, existing in low level of development. [1]

\section{B. Private early childhood education lack of educational service agencies regulation,results in poor education.}

To meet the people's demand for early education of infants, policy support from the government to private education institutions, private education institutions came into being. In fact, early 0-3 years old infant education is a man-made object towards 0 -3 years old infants and its cultivation ,promoting 0-3 years old infants development of physical and mental health, enhancing the concept of educated man of science education and promoting the process of good parenting behavior. However, owing to the deficiency of perfect education policy and effective management measures on 0-3 years old infants education, which caused most private institutions pursuit for profit, and cater to parents as primary purpose, have low professional, provide low health care quality, and even many early education institutions in running have problems,such as running conditions crude, health conditions poor, security hidden more, charges chaos, teachers quality low, courses set not science, problem. [2], which led to the existing 0-3 years old infants services in institutions of education, service and guidance capacity cannot meet the infant development, practical needs of the parents and the community.

C. The kindergarten lead the community early childhood developmental delays, and sharp differences between the regions.

Kindergartens have the advantages of expertise, intelligence, space, education facilities and others.However, because it affected by the interests, ideas, resources, and other aspects in reality ,kindergartens are only responsible for infants and parents into the garden and for the education administrative department. At present, the kindergarten in the Community is affiliated with the administrative departments of education, responsible for 3-6 years old children (extended to 2 years old) care and education as well as parents of education guide, but guidance for 0-3 years old children and parents is almost blank. Advantage in kindergarten and resources attached to parenting, parent-child guidance station in kindergarten, community early childhood education base, is a new education model of current, and the focus of State education departments. However, currently only developed areas like Beijing and Shanghai are established gradually, due to differences in local economic development and community maturity, early education services in communities in the central region of 0-3 years old infants work more difficultly.

\section{Weak early education research results, lack of theory and practice.}

0-3-year-old early education research in China is very weak, "community-based education for 0 -3years old children services" research results in the field are small, and lacks theory guide a lot. Practically, lack of guidance for 0-3 years old infants education institutions and national, provincial, municipal, County, Township and village and no sound, rich level of guidance system, the tasks of 0-3 years old infant care and education can only be borne by the family. While most parents lack the critical period of Brain Science and the development of theoretical knowledge, personal experience with parental lack of scientific concepts and methods of child-rearing. Some think this phase of the child was a "Tabula Rasa", and some better conditions for families, consciously took the child to early education institutions, that is to receive a quality education. As everyone knows, the most important thing for parents is to learn science concepts and methods of child-rearing, conservation and promote the development of children abilities in everyday life. [3]

\section{THE STRATEGY TO PROMOTE THE DEVELOPMENT OF INFANT EARLY EDUCATION IN COMMUNITY}

A. Integrate resources, to build community service system of early education for 0-3 years old infant .

Education is a systematic project, families, educational institutions and communities are the main places of activity of infant life, linked closely, need for close and effective cooperation, to effect in infants and young children who have a good education. Full integration of community 
resources, early education included in the local development of 0-3 years old infants general education development planning, dovetailed with the kindergarten planning and construction, make overall arrangements. Establishment of Government-led, Division is responsible for the education and health sector, related sectors to participate in working groups, improve the working mechanisms for interdepartmental cooperation. To give full play to the kindergarten teachers ' training colleges, preschool teaching and research institutions, maternity and child care institutions and kindergarten resources, strengthen coordination and cooperation, for the parents to carry out various forms of nonprofit early education of infants,to promote infants' development in health, emotion and sociality, language, intelligence and other aspects .

Meanwhile, communities should step up support, provide the guarantee of necessary human, physical, financial and other aspects, improve the conditions of Service Center and set up effective infant early education system. So, it will help engage in multiple forms of early childhood education service center, and residents nearby to use conventional early education services.

B.Strengthening early childhood advocacy and raising public awareness of the early education for infants.

Relevant administrative departments should be aware of future trend of early childhood development, increase emphasis on early education of infants and young children, carry out research and develop in line with local community early childhood development policy. Early childhood development to create a favorable social environment for the community, the community scattered children enjoy equitable access to educational resources, in particular the economic conditions are not ideal for families in the community.

Publicity as possible to enhance the community's knowledge of the early years, early childhood activities for parents to understand the community's purpose, changing neighborhood and service center to carry out passive situation, parents parenting philosophy, promoting community residents ' active participation in the community early education of infants and young children.Make Community education work effectively and promote early education as a social consensus.

\section{Promoting the construction of specialized personnel, and improving the quality of community} education.

Early education of 0-3 years old infants is a branch of the education system, and the development of the children has its particularity at this stage, so the education for this stage is different from the others. This career requires a professional practitioners, rather than a senior nurse. To alleviate the deficiency of community early education staff and the lack of expertise, it should strengthen the construction of early childhood professionals. To build a highly qualified professional team personnel, there are two ways through education and training. One way is rely on University of preschool education professional and medical professional to explore 0-3-year-old infants early education practitioners of training coursing and training modes,practitioners qualification and professional quality; the other way is choose high quality teachers from existing teachers who have solid preschool education professional theory, work patience detailed, small age class shift experience richly, and been a mother before,and then will have a 0-3 years old early education and guide of system training. And then it will improve early education teachers and form a professional teams for 0-3 years old infants, promote the entire community early childhood practitioners professional capacity, and strengthen capacities in health and care education in community .

\section{Relying on the community kindergarten to promote the work of 0-3-year-old infant's early educational guidance.}

Kindergarten are parts of the community in the community. Kindergarten have advantages in preschool education expertise, intelligence, space, education facilities and so on, especially demonstrative kindergarten.Demonstrative kindergarten is a preschool educational institution which play an demonstration role of kindergarten for other kindergarten, thus setting community Guide Center for early education of 0-3-year-old infants is the most suitable and most quickly and easily 
build 0-3 years old ways to entities and early education services hub in community. United States scholar Olson suggested that schools should not be divorced from the community's cultural Islands, it should take the initiative to set up community bridge, dedicated to solving community problems. Therefore, early education services in communities in the central region of 0-3 years old infants work without the support of kindergarten, kindergartens should move from outside to inside, become the center of community 0-3years old infants education service. [4] This can enhance the social impact of kindergarten, meanwhile, improve the resource efficiency of kindergarten via many ways, such as offering 0-3 years old infants fun Park (class) to "5+2" mode of operation, namely five days in the Park routine teaching kindergarten, infant diaspora community-oriented open during the weekend, achieving win-win economic benefits and social benefits.

\section{CONCLUSION}

In short, early education of 0-3 years old infant is with strong community, closely associated with the community. Relevant departments should value and support the development of the community 0-3 years old infant's early education from various sectors,building a platform for early education to form influence.Meanwhile,to strengthen its research,practice richly,gather experience, and gradually extended, then explore a suitable form for local community children and caretakers of early education, so as to lay a good foundation for people's lifelong development.

\section{ACKNOWLEDGMENT}

The research work was supported by the project of Sichuan Early Development and Education Research Center for 0-3 Years Old Children (SCLS16-025), and the planning fund project of Ministry of Education for humanities and social science (16YJA880032).

\section{REFERENCES}

[1] Zheng Jiancheng: On the Situation of Service for Early Education in Communities and the Function of Exemplary Kindergartens, Journal of Preschool Education Research (2008).

[2] Xu Xiaohui: 0-3 infant care and education , The Open University of China Publishers,(2012).

[3] Jin Yan. Use of , To promote the Kids for all-round development by using of community resources, with the aid of home together. Journal of Preschool Education Research, 2007, (7-8)

[4] Chen Hongmei, Jin Jinxiu: From Outside to Inside--the Opinion about Kindergartens to Become Community 0-3 infant' Early Education Service Center, Journal of Preschool Education Research (2009). 